\title{
PRODUÇÃO E QUALIDADE DOS FRUTOS DE CLONES DE LARANJEIRA-'PERA' NO NORTE DO PARANÁ ${ }^{1}$
}

\author{
ZULEIDE HISSANO TAZIMA², CARMEN SILVIA VIEIRA JANEIRO NEVES ${ }^{3}$, \\ INÊS FUMIKO UBUKATA YADA ${ }^{4}$, RUI PEREIRA LEITE JÚNIOR ${ }^{5}$
}

RESUMO - Na implantação dos pomares cítricos, é importante o uso de cultivares adaptadas às condições locais, de forma a assegurar boa produtividade. A laranjeira-'Pera’ [Citrus sinensis (L.) Osbeck] é a cultivar mais importante da citricultura brasileira. O objetivo deste trabalho foi avaliar três clones de laranjeira-'Pera' do Banco Ativo de Germoplasma de Citros (BAG-Citros) do Instituto Agronômico do Paraná - IAPAR (acessos I-58 'Pera Vacinada 3’, I-59 ‘Pera Vacinada 4’ e I-89 'Pera Bianchi’) enxertados sobre o limoeiro'Cravo’ (Citrus limonia Osbeck), nas condições edafoclimáticas de Londrina-PR. As plantas cultivadas no espaçamento 7,0 m x 6,0 m foram conduzidas sem irrigação e avaliadas em relação à produção por planta e às características físico-químicas dos frutos. Os clones de laranjeira I-58 'Pera Vacinada 3', I-59 'Pera Vacinada 4' e I-89 ‘Pera Bianchi’ apresentaram, em nove safras, produção média anual por planta de 164,10 kg, 133,96 kg e 131,03 kg, respectivamente. Não houve diferença estatística entre os clones para as variáveis estudadas nas 14 safras. A qualidade dos frutos foi a seguinte: para I-58 'Pera Vacinada 3' e I-59 'Pera Vacinada 4' e I-89 'Pera Bianchi’, respectivamente: 159,6 g, 149,9 g e 150,9 g para massa de fruto; sólidos solúveis de $11,16{ }^{\circ}$ Brix, $10,98{ }^{\circ}$ Brix e $10,65{ }^{\circ}$ Brix; acidez titulável de 1,07\%, 1,12\% e 0,99\%; teor de suco de 50,8\%, 52,9\% e 49,7\%; ratio de 10,6; 10,0 e 10,9 e índice tecnológico de 2,31; 2,34 e 2,15 kg de sólidos solúveis por caixa.

Termos para indexação: Citrus sinensis, produtividade, sólidos solúveis, acidez.

\section{YIELD AND FRUIT QUALITY OF 'PERA' ORANGE TREE ACCESSIONS IN NORTHERN PARANÁ, BRAZIL}

\begin{abstract}
The use of adapted cultivars to the local conditions is important when establishing citrus orchards to ensure good yield. The sweet orange 'Pera' [Citrus sinensis (L.) Osbeck] is the most important cultivar to the Brazilian citriculture. The aim of this study was to evaluate three clones of 'Pera' orange trees from the Citrus Active Germplasm Bank of the Instituto Agronômico do Paraná - IAPAR ('Pera Vacinada 3' accession I-58, 'Pera Vacinada 4' accession I-59 and 'Pera Bianchi' accession I-89) in the edafoclimatic conditions of Londrina, Paraná, Brazil. The plants were grafted on 'Rangpur’ lime (Citrus limonia Osbeck), spaced $7.0 \mathrm{~m}$ x $6.0 \mathrm{~m}$ and maintained without irrigation. The evaluations were based on plant yield and physical-chemical fruit characteristics. The clones of orange tree I-58 'Pera Vacinada 3', I-59 'Pera Vacinada 4' and I-89 'Pera Bianchi’ presented annual yield per plant during nine crop seasons of $164.10 \mathrm{~kg}, 133.96 \mathrm{~kg}$ and $131.03 \mathrm{~kg}$, respectively. There was no significant difference among the clones for the variables studied during 14 crop seasons. The fruit quality was as follows for I-58 'Pera Vacinada 3', I-59 'Pera Vacinada 4' and I-89 'Pera Bianchi', respectively: fruit mass of $159.6 \mathrm{~g}, 149.9 \mathrm{~g}$ and $150.9 \mathrm{~g}$; soluble solids of 11.16 ${ }^{\circ}$ Brix, $10.98{ }^{\circ}$ Brix and $10.65{ }^{\circ}$ Brix; titratable acidity of $1.07 \%, 1.12 \%$ and $0.99 \%$; juice content of $50.8 \%$, $52.9 \%$ and $49.7 \%$; ratio of 10.6; 10.0 and 10.9; and technological index of 2.31; 2.34 and $2.15 \mathrm{~kg}$ of soluble solids per box.
\end{abstract}

Index terms: Citrus sinensis, production, soluble solids, acidity.

\footnotetext{
1(Trabalho 024-09). Recebido: 07-01-2009. Aceito para publicação em: 15-06-2009.

${ }^{2}$ Eng $^{\mathrm{a}}$ Agr $^{\mathrm{a}}$, Doutoranda, Pesquisadora, Instituto Agronômico do Paraná - IAPAR, Área de Ecofisiologia, C.P. 481, CEP 86001-970, ,Londrina-PR. E-mail: zuleide@iapar.br

${ }^{3}$ Eng $^{a}$ Agr $^{\text {a }}$, Dr ${ }^{\text {a }}$, Professora, Universidade Estadual de Londrina-UEL, Depto. de Agronomia, C.P. 6001 - CEP 86051-990, LondrinaPR. Bolsista em Produtividade do Conselho Nacional de Desenvolvimento Científico e Tecnológico-CNPq. E-mail: csvjneve@uel.br ${ }^{4}$ Lic. Matemática, M.Sc., Pesquisadora, Instituto Agronômico do Paraná - IAPAR, Área de Biometria, C.P. 481, CEP 86001-970, Londrina-PR. E-mail: inesyada@iapar.br

${ }^{5}$ Eng $^{\circ}$ Agr $^{\circ}$, Dr, Pesquisador, Instituto Agronômico do Paraná - IAPAR, Área de Proteção de Plantas, C.P. 481, CEP 86001-970, Londrina-PR. E-mail: ruileite@iapar.br
} 


\section{INTRODUÇÃO}

O Brasil é o principal produtor mundial de laranjas, com 18.279.309 toneladas em 2007, o que representa 28,6\% do total mundial (FAO, 2007). A citricultura brasileira ocupa área de 799.356 ha e está concentrada no Estado de São Paulo, que participa com a produção de 14.367.011 toneladas de frutos, o que representa 78,6\% da produção nacional, enquanto o Paraná é o quinto produtor com 2,2\% (IBGE, 2006).

A implantação da citricultura no noroeste do Estado teve início em 1989 (Auler et al., 2008), e tem sido de grande importância para a fruticultura paranaense (Tazima et al., 2008). Dados referentes à safra de 2006 demonstram que a área cultivada com laranja foi de 16.700 ha, produção de 412.300 toneladas e produtividade média de $24.688 \mathrm{~kg} / \mathrm{ha}$. A laranja ocupou o primeiro lugar entre as frutas produzidas no Paraná, com 33,09\% (Andrade, 2007). A produção atende às três indústrias instaladas no Estado, que processam os frutos e produzem suco concentrado congelado de laranja destinado à exportação.

O Instituto Agronômico do Paraná - IAPAR, é o órgão responsável pela recomendação de cultivares para o Estado e tem introduzido diversos materiais no seu Banco Ativo de Germoplasma de Citros (BAG Citros), onde mantém os diferentes genótipos para avaliação e determinação da adaptação às condições edafoclimáticas do Paraná. O BAG é de fundamental importância para a pesquisa, pois possibilita a caracterização e a avaliação dos diferentes materiais, dando ênfase ao estudo da adaptação de espécies e variedades ao ambiente de cultivo. Esses conhecimentos são imprescindíveis à obtenção de materiais a serem utilizados comercialmente, ampliando o número de cultivares para o mercado de frutas frescas ou de produção de suco (Leite, 2004).

As cultivares de laranja-doce [Citrus sinensis (L.) Osbeck] recomendadas para cultivo no Estado são: 'Pera', 'IAPAR 73’, 'Folha-Murcha', 'Valência', 'Navelina', 'Shamouti', 'Salustiana', 'Cadenera' e 'Jaffa’ (Tazima \& Leite Júnior, 2002; Tazima \& Leite Júnior, 2000; Leite Júnior, 1992). A laranjeira- 'Pera’ é a mais importante cultivar brasileira, utilizada pela indústria e para os mercados interno e externo de fruta fresca (Donadio et al., 1999). Apesar de reconhecida como a cultivar brasileira por excelência, sua origem permanece obscura (Donadio et al., 1995). É de maturação de meia-estação e é cultivada em escala comercial somente no Brasil (Pio et al., 2005). Sua grande população de plantas explica o aparecimento e a seleção de novos clones da cultivar, surgidos, na maioria, por variação gemária (Salibe et al., 2002). O porta-enxerto utilizado predominantemente ainda é o limoeiro-‘Cravo’ para todas as cultivares (Auler et al., 2008).

Leite Júnior (1992) relata que a laranjeira'Pera' apresenta intolerância ao vírus da tristeza, não se adapta às regiões mais frias do Paraná e comportase como moderadamente resistente ao cancro-cítrico, característica fundamental no manejo integrado da doença. Müller et al. (1999), por meio do programa de pré-imunização ou proteção cruzada de clones da cultivar Pera, com isolados fracos do vírus, possibilitaram a exploração da cultivar. Outros clones, portadores naturais de estirpes atenuadas do vírus da tristeza, também foram selecionados e estão em cultivo no País.

Mesmo pertencente à mesma cultivar, clones de laranjeira-'Pera' selecionados no Brasil podem apresentar características diferentes em diversos locais. As diferenças obtidas neste caso podem ser atribuídas às condições edafoclimáticas de cada local e aos clones avaliados (Donadio et al., 1995). Portanto, como as informações sobre o comportamento da cultivar no norte do Estado ainda não foram relatadas, o objetivo deste trabalho foi estudar a produção e as características físico-químicas de frutos de três clones de laranjeira-'Pera’.

\section{MATERIAL E MÉTODOS}

As plantas de laranja-'Pera' enxertadas sobre o porta-enxerto limoeiro- 'Cravo’ (Citrus limonia Osbeck) fazem parte do BAG Citros da Estação Experimental do IAPAR, no município de LondrinaPR, implantado em Latossolo Vermelho distroférrico, com altitude de $585 \mathrm{~m}$ e coordenadas 2321'34” S e $51^{\circ} 09^{\prime} 53^{\prime}$ 'W. O clima da região é do tipo Cfa e as temperaturas médias, da máxima e mínima, são $27,3^{\circ} \mathrm{C}$ e $16^{\circ} \mathrm{C}$, respectivamente; a precipitação média anual é de $1.588 \mathrm{~mm}$, e a umidade relativa média é de 70,6\% (Figura 1) (IAPAR, 2008).

Foram avaliados três acessos de laranjeira'Pera’: ‘Vacinada 3' acesso I-58, 'Vacinada 4' acesso I-59 e 'Bianchi’ acesso I-89, introduzidos da coleção de citros da Faculdade de Ciências Agronômicas da Universidade Estadual Paulista-UNESP/Botucatu SP e plantados em dezembro de 1981 (I- 58 e I-59) e maio de 1983 (I-89), em espaçamento de 7,0 m x $6,0 \mathrm{~m}$, correspondendo a 238 plantas por hectare. $\mathrm{O}$ delineamento experimental foi inteiramente ao acaso, cada acesso foi representado por três repetições e uma planta por parcela, cultivadas sem irrigação. Os tratos culturais preconizados, como pulverizações 
preventivas com produtos à base de cobre para o cancro-cítrico, controle de outras doenças e pragas, adubação para a formação da planta e produção de frutos, controle de plantas invasoras com o uso de herbicida na linha de plantio e roçadeira na entrelinha, foram realizados conforme as recomendações para a região. Para a avaliação da produção de frutos por planta e da massa média do fruto (MF) por ocasião da colheita, foram realizadas a contagem e a pesagem dos frutos por um período de nove safras, da quarta à décima segunda safra.

Para a análise química dos frutos, foram coletadas amostras contendo 10 frutos da parte externa das plantas, à altura entre $1,0 \mathrm{~m}$ e $2,0 \mathrm{~m}$. A colheita foi realizada a partir da primeira quinzena de junho até agosto, a cada 30 dias, por um período de 14 safras. A extração do suco foi realizada com extratora Croydon ${ }^{\circledR}$, modelo ES4EA-B60000. O teor de sólidos solúveis (SS) foi determinado pela leitura direta em refratômetro Atago ${ }^{\circledR}$. A acidez titulável (AT) foi determinada por titulação de $25 \mathrm{~mL}$ de suco, com solução de hidróxido de sódio a 0,1 N (AOAC, 1990), obtendo-se o resultado em porcentagem de ácido cítrico. O ratio foi calculado pela relação aritmética entre sólidos solúveis e acidez titulável (SS/AT).

O rendimento em suco, expresso em porcentagem, foi determinado através da relação: $(\mathrm{MS} / \mathrm{MF}) \times 100$, onde MS = massa do suco $(\mathrm{g})$ e MF = massa da fruta (g). O índice tecnológico (IT) ou quantidade de sólidos solúveis no suco, em uma caixa de 40,8 kg ( $\mathrm{kg}$ de SS.caixa ${ }^{-1}$ ), foi calculado conforme a fórmula de Di Giorgi et al. (1990): IT = [rendimento em suco x sólidos solúveis x 40,8] / 10.000, onde: IT= índice tecnológico; rendimento em suco = relação $\mathrm{MS} / \mathrm{MF} \mathrm{x}$ 100; sólidos solúveis = teor de sólidos solúveis; $40,8 \mathrm{~kg}=$ peso-padrão da caixa de colheita de laranja.

Os dados obtidos foram submetidos à análise de variância, e as médias de produção anual de frutos por planta, a massa do fruto, o teor de sólidos solúveis, a acidez titulável, o ratio, o rendimento em suco e o índice tecnológico foram comparados pelo teste de Tukey, a 5\% de probabilidade.

\section{RESULTADOS E DISCUSSÃO}

A produção média anual do clone I-58 'PeraVacinada 3' foi superior à do I-59 'Pera-Vacinada 4' na $5^{\mathrm{a}}$ e na $7^{\mathrm{a}}$ safras, e superior à de I-89 'Pera-Bianchi' na $5^{\mathrm{a}}$ safra (Figura 2). Quanto à produção do clone I-59 'Pera-Vacinada 4', verificou-se que esta foi maior que a obtida com 'Pera-Bianchi' na $5^{\mathrm{a}}$ e na $6^{\mathrm{a}}$ safras, porém a produção deste clone foi menor que a de 'Pera Bianchi' na 7 a safra. Em relação às demais safras, não houve diferenças significativas entre os clones avaliados (Figura 2). A produção média das nove safras foi de 131,03 kg para o clone 'Pera-Bianchi', 133,9 kg para o clone 'Pera-Vacinada 4', e 164,10 kg para o clone 'Pera-Vacinada 3', correspondendo a 3,21; 3,28 e a 4,02 caixas de $40,8 \mathrm{~kg}$ por planta, respectivamente, sem diferença significativa entre os clones. Essa produção supera a média nacional, que é de 2,0 caixas por planta (Machado et al., 2005). Para o clone 'Bianchi', Teófilo Sobrinho et al. (1990), em trabalho realizado em Araraquara (SP), Teófilo Sobrinho et al. (2001), em Cordeirópolis (SP), e Domingues et al. (2004), também em Cordeirópolis (SP), obtiveram produção média por planta de 80,40 $\mathrm{kg}, 74,10 \mathrm{~kg}$ e $64,0 \mathrm{~kg}$, respectivamente, enquanto os demais clones avaliados, também vacinados ou premunizados, apresentaram médias que variaram de 44,3 kg para 'Premunizado 1212' a 86,4 kg para 'IAC 2000'. No entanto, segundo Figueiredo (1991), a produção estimada para a cultivar Pera no Estado de São Paulo, é de 250 kg por planta (com base na média obtida junto às indústrias processadoras produtoras de suco), valor bem acima das médias obtidas neste trabalho e pelos demais autores citados. No presente trabalho, de agosto a setembro, as médias das temperaturas mínimas e do índice pluviométrico mais baixo nos meses de julho a agosto (Figura 1) apresentaram condições favoráveis ao florescimento.

As variáveis massa do fruto, sólidos solúveis, acidez titulável, rendimento em suco e índice tecnológico dos acessos estudados não apresentaram diferença estatística (Tabela 1) para as condições avaliadas. A massa de fruto obtida no presente trabalho foi de 159,64 g para o clone I-58 'PeraVacinada 3', e de 149,85 g para I-59 'Pera-Vacinada 4', enquanto para I-89 'Pera-Bianchi' foi de 150,86 $\mathrm{g}$, estando acima da massa média do fruto para o Estado de São Paulo, que é de 145 g (Figueiredo, 1991). Teófilo Sobrinho et al. (1990), estudando os clones de laranjeira 'Pera-Bianchi', 'Premunizado 1743', 'Premunizado 1212' e 'EEL', obtiveram massa de fruto de 149 g, 166 g, 165 g e 183 g, respectivamente, dados semelhantes aos relatados por Teófilo Sobrinho et al. (1977). Domingues et al. (1999), em Cordeirópolis, citaram a menor massa média do fruto para a 'Pera-Bianchi' (136,48 g), 129,26 g para 'Pera-Premunizada 1212' e 151,66 g para 'Pera-EEL'.

O rendimento em suco obtido foi de $49,68 \%$ para 'Pera-Bianchi', 50,84\% para 'Pera-Vacinada 3' e 52,86\% para 'Pera-Vacinada 4', valores bem 
próximos aos 52\% apresentado por Figueiredo (1991). Teófilo Sobrinho et al. (1990) obtiveram valores mais altos do que o relatado por Figueiredo (1991), sendo de 58,8\% para 'Bianchi', 60,6\% para 'Premunizado 1743', 58,4\% para 'Premunizado 1212' e 56,5\% para 'EEL', enquanto Domingues et al. (1999) relataram rendimento em suco de 48,52\% para 'Bianchi' e acima de 49\% para 'PeraEEL’ e ‘Pera-Premunizada 1212’. Viégas (1991) cita valores de 40 a 45\% como aceitáveis para o rendimento em suco para outras cultivares (Hamlin 41\%). A massa do fruto está diretamente relacionada à disponibilidade hídrica do solo, normalmente perdem massa nos meses de inverno, ocorrendo em diversos casos murchamento acentuado e, com o retorno da disponibilidade de água, a partir das chuvas da primavera, há rápido e contínuo ganho de massa ou tamanho até sua colheita (Pozzan \& Triboni, 2005), favorecendo também maior porcentagem de rendimento em suco.

Figueiredo (1991) constatou teor de SS de 11,8 ${ }^{\circ}$ Brix para a cultivar Pera. Teófilo Sobrinho et al. (1990) observaram os menores valores para SS; 8,57 para 'Bianchi', 9,35 para 'Pera-EEL', 8,86 para 'Pera-Premunizada 1212' e 9,14 para 'Pera-Premunizada 1743'. Domingues et al. (1999) demonstraram valores que variaram de 12,62 para 'EEL' e 'Premunizado 1743', para 12,93 a 14,17 de 'Bianchi' e 'Pera-Premunizada 1212', respectivamente. Neste trabalho, foram obtidos valores de SS intermediários aos citados, 11,16 para I-58 'Pera-Vacinada 3', 10,89 para I-59 'Pera-Vacinada 4' e 10,65 para I-89 'PeraBianchi'. Os valores de SS baixos e acidez mais elevada, encontrados neste trabalho, podem estar relacionados ao período de amostragem dos frutos, que ocorreu nos meses de junho, julho e agosto, sendo posteriormente calculada a média, indicando que os frutos avaliados não haviam atingido a completa maturação. Albrigo (1992) relata que, no final do verão, há acúmulo bastante alto de açúcares, os sólidos solúveis continuam a aumentar e a acidez diminui, fase em que o fruto cítrico se apresenta com qualidade comestível. Quando o crescimento do fruto é razoavelmente rápido, a quantidade dos sólidos solúveis pode aumentar, mas sua concentração pode permanecer estável ou diluir-se levemente devido ao rápido aumento do teor de água.

As quantidades em kg de sólidos solúveis por caixa ou índice tecnológico para I-58 'Pera-Vacinada 3', I-59 'Pera-Vacinada 4' e I-89 'Pera- Bianchi', foram 2,31; 2,34 e 2,15, respectivamente, ficando abaixo dos 2,5 kg.cx-1 citados por Figueiredo (1991).
Em dados coletados de 1986 a 1988, Teófilo Sobrinho et al. (1990) obtiveram média de 2,05 kg para 'PeraBianchi', 2,25 kg para 'Premunizado 1743', 2,11 kg para 'Premunizado 1212’e 2,15 de sólidos solúveis para 'EEL', valores próximos aos obtidos neste trabalho. Domingues et al. (1999) obtiveram 2,55 para 'Pera-Bianchi' e 'Pera-EEL', 2,59 para 'PeraPremunizada 1743' e 2,83 para 'Pêra Premunizada 1212'. As cultivares destinadas à indústria, como as laranjas 'Hamlin', 'Pera', 'Natal' e 'Valência', apresentam valores médios de sólidos solúveis (kg/ caixa) entre 2,2 e 2,7 (Di Giorgi et al., 1990).

A variável acidez titulável relatada por Figueiredo (1991) foi de 0,95\% para a cultivar Pera, enquanto Teófilo Sobrinho et al. (1990) citaram valores entre 0,63 ('Bianchi') e 0,84 ('Premunizado 1212'). Domingues et al. (1999) observaram valores de 1,21 para 'Bianchi', 1,13 para 'Pera-EEL', 1,45 para 'Pera-Premunizada 1212' e 1,34 para 'PeraPremunizada 1743'. No presente trabalho, foram obtidos valores de AT de 1,07, 1,12 e 0,99 para I-58 'Vacinada 3', I-59 ‘Vacinada 4' e I-89 'Pera-Bianchi', respectivamente. Nas cultivares com período de maturação de meia-estação, a colheita antecipada pode acarretar prejuízos na qualidade do suco, como a presença de amargor acentuado. Conforme Chitarra \& Chitarra (2005), a acidez dos frutos tende a decrescer com a utilização dos ácidos orgânicos na atividade respiratória, que é intensa à medida que segue o crescimento e a maturação dos frutos. Portanto, frutos mantidos por mais tempo na planta teriam sua maturação completa, favorecendo um incremento nos valores de ratio.

Os valores de ratio obtidos foram de 10,61 para I-58 'Pera-Vacinada 3', 10,01 para I-59 'PeraVacinada 4’ e 10,90 para I-89 'Pera-Bianchi' (Tabela 1). Pozzan \& Triboni (2005) relatam que sucos com ratio entre 14 e 16 são os mais apreciados pelos consumidores em todo o mundo, devido ao equilíbrio em termos sensoriais, entre o teor de açúcares e ácidos. Petto Neto \& Pompeu Júnior (1987) citam que, apesar de a variação do valor de ratio que a indústria processa, ser de 6 a 20, o intervalo ideal é de 11 a 14. Figueiredo (1991) relata que, para a cultivar Pera, o ratio é de 12,5; no entanto, Teófilo Sobrinho et al. (1990) observaram ratio variando de 10,83 para 'Premunizado 1212' a 14,20 para 'EEL', Domingues et al. (1999) constataram ratio de 10,82 para 'PeraPremunizada 1212', 12,50 para 'EEL', 11,71 para 'Bianchi', e 10,83 para 'Premunizada 1743', valores que se aproximam dos obtidos neste trabalho. 


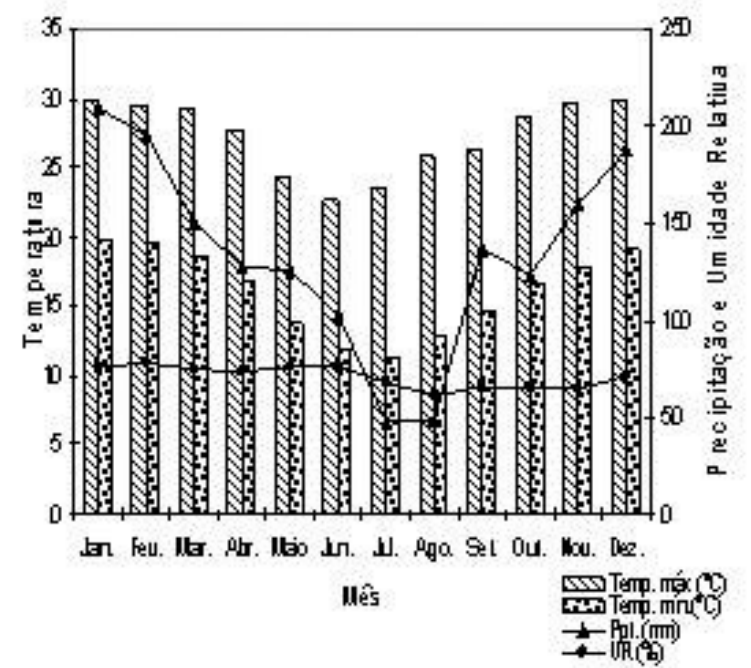

FIGURA 1 - Média das temperaturas máxima e mínima, precipitação e umidade relativa da Estação Experimental do Instituto Agronômico do Paraná - IAPAR, Londrina-PR, para o período de 1983 a 2000.

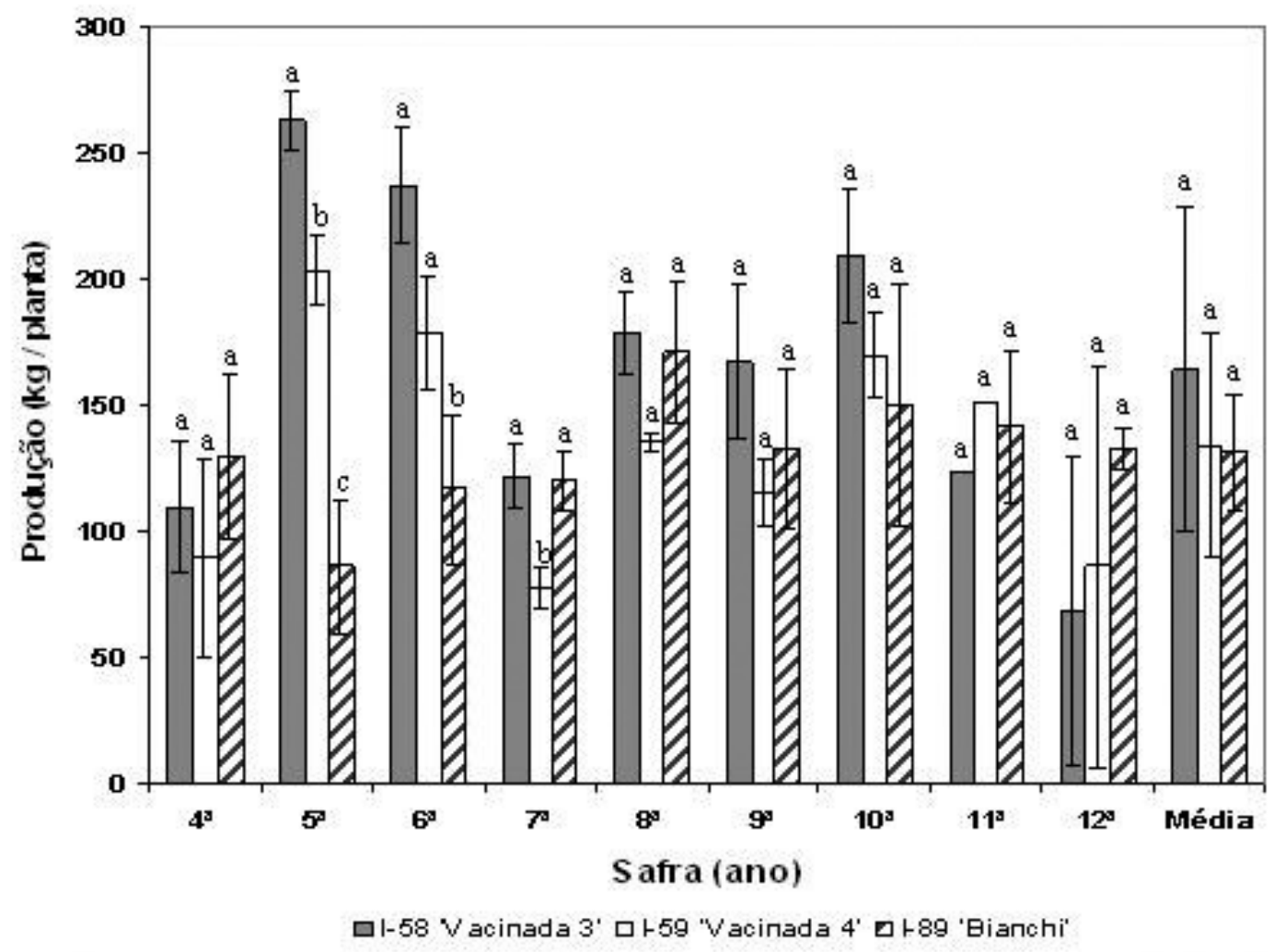

FIGURA 2 - Produção média anual (kg.pl-1), Desvio-Padrão (DP), Média e teste de Tukey de nove safras de três clones de laranjeira-'Pera’ na Estação Experimental do IAPAR, Londrina-PR, de 1989 a 1997. 
TABELA 1-Parâmetros médios (M), desvio-padrão (DP) e coeficiente de variação (CV) da massa do fruto (MF), sólidos solúveis (SS), acidez titulável (AT), ratio (SS/AT), rendimento em suco (Suco) e índice tecnológico (IT) de frutos de três clones de laranjeira-‘Pera’ na Estação Experimental do IAPAR, Londrina-PR. 1987 a 2000.

\begin{tabular}{|c|c|c|c|c|c|c|c|c|c|c|c|c|}
\hline \multirow[t]{2}{*}{$\begin{array}{c}\text { Clone de } \\
\text { Laranjeira- } \\
\text { 'Pera' }\end{array}$} & \multicolumn{2}{|c|}{$\begin{array}{l}\text { MF } \\
\text { (g) }\end{array}$} & \multicolumn{2}{|c|}{$\begin{array}{c}\text { SS } \\
\left({ }^{\circ} \text { Brix) }\right.\end{array}$} & \multicolumn{2}{|c|}{$\begin{array}{l}\text { AT } \\
(\%)\end{array}$} & \multicolumn{2}{|c|}{$\begin{array}{c}\text { Ratio } \\
\text { (SS/AT) }\end{array}$} & \multicolumn{2}{|c|}{$\begin{array}{r}\text { Suco } \\
(\%) \\
\end{array}$} & \multicolumn{2}{|c|}{$\begin{array}{c}\text { IT } \\
\text { kg.cx } \\
\end{array}$} \\
\hline & $\mathrm{M}$ & $\mathrm{DP}$ & $\mathrm{M}$ & $\mathrm{DP}$ & $\mathrm{M}$ & DP & M & $\mathrm{DP}$ & $\mathrm{M}$ & DP & $\mathrm{M}$ & DP \\
\hline I-58 ‘Vac. 3’ & 159,64 & 22,95 & 11,16 & 1,37 & 1,07 & 0,15 & 10,61 & 1,56 & 50,84 & 2,90 & 2,31 & 0,34 \\
\hline I-59 ‘Vac. 4’ & 149,85 & 29,50 & 10,89 & 0,83 & 1,12 & 0,24 & 10,01 & 1,56 & 52,86 & 4,31 & 2,34 & 0,24 \\
\hline I-89 Bianchi’ & 150,86 & 15,03 & 10,65 & 0,86 & 0,99 & 0,12 & 10,90 & 1,07 & 49,68 & 3,70 & 2,15 & 0,22 \\
\hline $\mathrm{CV}(\%)$ & \multicolumn{2}{|c|}{15,03} & \multicolumn{2}{|c|}{9,73} & \multicolumn{2}{|c|}{16,80} & \multicolumn{2}{|c|}{13,45} & \multicolumn{2}{|c|}{7,17} & \multicolumn{2}{|c|}{11,96} \\
\hline
\end{tabular}

Não houve diferença significativa entre as médias dos clones, ao nível de 5\% de probabilidade, pelo teste de Tukey.

\section{CONCLUSÕES}

1-Nas condições do norte do Paraná, os três clones apresentam o mesmo comportamento para produção média anual por planta nas nove safras de $131,03 \mathrm{~kg}$ para o clone 'Pera-Bianchi', 133,96 kg para o clone 'Pera-Vacinada 4', e de $164,10 \mathrm{~kg}$ para o clone Pera-Vacinada 3'.

2-As médias das 14 safras para as variáveis massa do fruto (MF), teor de sólidos solúveis (SS), acidez titulável (AT), ratio (SS/AT), rendimento em suco (Suco) e o índice tecnológico (IT) também não diferem para os três clones.

\section{AGRADECIMENTOS}

Agradecemos aos colaboradores Sydnei Dias dos Santos, Naodi Komori, Lucinéia Maria da Silva e José Antonio de Oliveira, pelo apoio prestado na condução dos trabalhos e avaliações.

\section{REFERÊNCIAS}

AULER, P.A.M.; FIDALSKI, J.; PAVAN, M.A.; NEVES, C.S.V.J. Produção de laranja 'Pera' em sistemas de preparo do solo e manejo nas entrelinhas. Revista Brasileira de Ciência do Solo, Campinas, v. 9, n. 1, p.363-374, 2008.

AULER, P.A.M.; FIORI-TUTIDA, A.C.G.; TAZIMA, Z.H. Comportamento da laranjeira-'Valência' sobre seis porta-enxertos no noroeste do Paraná. Revista Brasileira de Fruticultura, Jaboticabal, v.30, n. 1, p.229-234, 2008.

ANDRADE, P.F.S. Análise da conjuntura agropecuária: safra 2007/2008. Curitiba: SEAB/DERAL, 2007. 10 p.
AOAC. - ASSOCIATION OF ANALYTICAL CHEMISTS. Official methods of analysis. $15^{\text {th }} \mathrm{ed}$. Arlington: AOAC, 1990. 1298 p.

CHITARRA, M.I.F.; CHITARRA, A.B. Pós-colheita de frutos e hortaliças: fisiologia e manuseio. 2. ed. Lavras: UFLA, 2005. 783 p.

DI GIORGI, F.; IDE, B.Y.; DIB, K.; MARCHI, R.J.; TRIONI, H. DE R.; WAGNER, R.L. Contribuição ao estudo do comportamento de algumas variedades de citros e suas implicações agroindustriais. Laranja, Cordeirópolis, v. 11, n. 2, p. 567-612, 1990.

DOMINGUES, E. T. et al. Caracterização de onze clones de laranja-'Pera'e seis variedades assemelhadas. Laranja, Cordeirópolis, v. 25, n. 1, p. 111-138, 2004.

DOMINGUES, E. T.; MATTOS JUNIOR, D.; TEÓFILO SOBRINHO, J.; POMPEU JUNIOR, J.; FIGUEIREDO, J. O.; SUGAHARA, V. Y.. Seleção de clones de laranja 'Pera'e variedades assemelhadas quanto à qualidade do fruto e ao período de maturação. Laranja, Cordeirópolis, v. 20, n. 2, p. 433-455, 1999.

DONADIO, L. C. Laranja-pera. Jaboticabal: FUNEP, 1999. 51 p. (Boletim Citrícola, 11).

DONADIO, L. C.; FIGUEIREDO, J. O.; PIO, R. $\mathrm{M}$. Variedades cítricas brasileiras. Jaboticabal: FUNEP, 1995. 228 p.

FAO. FAOSTAT 2007. Disponível em: <http:// faostat.fao.org/site/567/DesktopDefault. aspx?PageID=567\#ancor $>$. Acesso em: 12 nov. 2008. 
FIGUEIREDO, J. O. Variedades copa de valor comercial. In: RODRIGUEZ, O. et al. (Ed.). Citricultura brasileira. 2.ed. Campinas: Fundação Cargill, 1991. v. 2, p.228-264.

IBGE. Produção Agrícola Municipal 2006; Malha municipal digital do Brasil: situação em 2006. Disponível em: <http://www.ibge.gov.br/estadosat/ temas.php?sigla=se\&tema=lavourapermanente200 6>. Acesso em: 12 nov. 2008.

IAPAR - INSTITUTO AGRONÔMICO DO PARANÁ. Monitoramento agroclimático do Paraná. Disponível em:<http://200.201.27.14/ Site/Sma/Estacoes_IAPAR/Estacoes_Parana.htm>. Acesso em: 05 nov. 2008.

LEITE, J. B. V. Coleções de fruteiras e sua importância para o melhoramento genético. 2004. Disponível em: <http:/www.todafruta.com.br/ todafruta/mostra_conteúdo.asp?conteúdo=6492\#> . Acesso em: 26 nov. 2007.

LEITE JÚNIOR, R. P. Cultivares de copa e portaenxertos. In: IAPAR. A citricultura no Paraná. Londrina: IAPAR, 1992. p. 91-116. (Circular, 72)

MACHADO, M.A.; CRISTOFANI, M.; AMARAL, A.M.; OLIVEIRA, A.C. Genética, melhoramento e biotecnologia de citros. In: MATTOS JÚNIOR, D.; NEGRI, J.D.;. PIO, R.M.; POMPEU JR., J. (Ed.). Citros. Campinas: Instituto Agronômico e Fundag, 2005. p. 221-277.

MÜLLER, G. W.; TARGON, M.L.P.N.; MACHADO, M. A. Trinta anos de uso de clone pré-imunizado 'Pera IAC’ na citricultura paulista. Laranja, Cordeirópolis, v. 20, n. 2, p. 399-408, 1999.

PETTO NETO, A.; POMPEU JUNIOR, J. Colheita, beneficiamento e transporte. In: CASTRO, P.R.C. (Ed.). Ecofisiologia da produção agrícola. Piracicaba: Associação Brasileira para Pesquisa da Potassa e do Fosfato, 1987. p. 893-897.

PIO, R. M.; FIGUEIREDO, J. O.; STUCHI, E. S.; CARDOSO, S. A.. B. Variedades copas. In: MATTOS JÚNIOR, D.; NEGRI, J.D.;. PIO, R.M.; POMPEU JR., J. (Ed.). Citros. Campinas: Instituto Agronômico e Fundag, 2005. p. 37-60.

POZZAN, M.; TRIBONI, H. R. Colheita e qualidade do fruto. In: MATTOS JÚNIOR, D.; NEGRI, J.D.; PIO, R.M.; POMPEU JR., J. (Ed.). Citros. Campinas: Instituto Agronômico e Fundag, 2005. p. 801-822.

RODRIGUEZ, O. Ecofisiologia dos citros. In:
CASTRO, P.R.C. (Ed.). Ecofisiologia da produção agrícola. Piracicaba: Associação Brasileira para Pesquisa da Potassa e do Fosfato, 1987. p. 149164.

SALIBE, A. A.; TEÓFILO SOBRINHO, J.; MÜLLER, G. W. Sinopse de conhecimentos e pesquisas sobre a laranja-'Pera'. Laranja, Cordeirópolis, v. 23, n. 1, p. 221-230, 2002.

TAZIMA, Z. H.; AULER, P.A.M.; NEVES, C.S.V.J.; YADA, I.F.U.; LEITE JUNIOR, R.P. Comportamento de clones de laranja-'Valência' na região norte do Paraná. Revista Brasileira de Fruticultura, Jaboticabal, v.30, n. 4, p.970-974, dez. 2008.

TAZIMA, Z. H.; LEITE JÚNIOR, R. P. Novos cultivares de citros para o Paraná. In: CONGRESSO BRASILEIRO DE FRUTICULTURA, 17., 2002, Belém. Anais... Belém: Sociedade Brasileira de Fruticultura, 2002. CD-ROM.

TAZIMA, Z. H.; LEITE JÚNIOR, R. P. IAPAR-73: Nova cultivar precoce de laranja (Citrus sinensis (L.) Osb.) para o Estado do Paraná. In: CONGRESSO BRASILEIRO DE FRUTICULTURA, 16., 2000, Fortaleza. Anais... Fortaleza: Sociedade Brasileira de Fruticultura, 2000. CD-ROM.

TEÓFILO SOBRINHO, J. ; FIGUEIREDO, J. O. de ; MÜLLER, G. W. ; LARANJEIRA, F.F.; SALIBE, A. A.; Laranja-'Pera IAC 2000'. Laranja, Cordeirópolis, v. 22, n. 2, p. 495-501, 2001.

TEÓFILO SOBRINHO, J. et al. Melhoramento de clones de laranjeira-'Pera' no Estado de São Paulo. In: CONGRESSO BRASILEIRO DE FRUTICULTURA, 4., 1977, Salvador. Anais... Salvador: Sociedade Brasileira de Fruticultura, 1977. p. 111-116.

TEÓFILO SOBRINHO, J. ; POMPEU JUNIOR, J. ; FIGUEIREDO, J. O. de ; DOMINGUES, E. T. ; TANNURI, F.Seleção de clones de laranjeira-Pera na região de Araraquara. Laranja, Cordeirópolis, v. 11, n. 1, p. 297-308, 1990.

VIEGAS, F. de C. P. A industrialização dos produtos cítricos. In: RODRIGUEZ, O.; VIEGAS, F. (Ed.). Citricultura brasileira. 2.ed. Campinas: Fundação Cargill, 1991. v. 2, p. 898-922. 